\title{
Analysis of Leaf Volatiles of Crabapple (Malus sp.) Individuals in Different Aphids' Resistance
}

\author{
Rong Wang, Xiang Shen, Chao Wang, Rui Ge, Zhen Zhang, Xiaojing Guo \\ College of Horticulture Science and Engineering, Shandong Agricultural University/State Key Laboratory for \\ Crop Biology Tai'an 271018, Shandong, China \\ Email: wangrong201109@163.com
}

Received 15 August 2014; revised 21 September 2014; accepted 21 October 2014

Copyright @ 2014 by authors and Scientific Research Publishing Inc.

This work is licensed under the Creative Commons Attribution International License (CC BY). http://creativecommons.org/licenses/by/4.0/

c) (i) Open Access

\section{Abstract}

The aim of this experiment was to analyze the leaf volatiles of crabapple (Malus sp.) individuals at different aphid's resistance, to ascertain the particular ingredients which has lure or aversion effects on aphid, and to provide reference for finding out a simple method to control effectively aphids. Volatiles of leaves from twenty-one different crabapple individuals were evaluated with the method of head space-solid phase micro-extraction and gas chromatography-mass spectrometry (HS-SPME-GC-MS). Volatiles profiles of them were then compared. There are one hundred eighty-six kinds of volatiles were detected with varied contents found in different individuals. And all plants contain eight kinds of common components: 3-Hexen-1-ol, acetate, (Z)-, 4-Hexen-1-ol, (Z)-, n-Decanal, n-Tetradecane, .alpha.-Farnesene, Diethyl Phthalate, Oxime-, methoxy-phenyl- and Dibenzofuran-, wherein the relative content of higher have 3-Hexen-1-ol, acetate, (Z)- and 4-Hexen1-ol, (Z)-. Specific volatile substances in high resistance plants contain 3-Hexenal, (Z)- and 2-Hexenal, (E)-. Leaf volatiles differ in twenty-one crabapple individuals. High resistance plants specific volatile substances contains 3-Hexenal, (Z)-, 2-Hexenal, (E)- and other small molecular volatile substances, and no-resistance plants all have .beta.-Farnesene.

\section{Keywords}

Crabapple (Malus sp.), Volatiles (VOCs), Aphids

\section{Introduction}

Plant volatile organic compounds, which are produced by the metabolism of secondary metabolites, vary be- 
tween individuals. Factors such as volatiles' type, quantity and concentration have a lure and aversion to insects and determine feeding direction of some infects. Plant volatile compounds are an important part of plant defense, therefore ascertaining volatiles' properties and function to phytophagous insects will contribute to put forward a new pest control strategies.

In recent years, the plant volatiles are widely concerned or receive extensive attention in the ecology and phytophagous insects study. Green leaf volatiles, which are produced by biosynthesis, such as leaves alcohol from unsaturated fatty acid, aldehyde and their derivatives, can affect many insect behaviors [1] [2]. The parasitic wasp looking for host in olfactory is influenced by a number of factors, in which plant volatiles plays a very important role [3] [4]. Sun Fan et al. [5] reported that there are $\alpha$-phellandrene, $\alpha$-Copaene and other volatiles from Korean pine main brunch tips that allure Pissodes nitidus positioning feeding compared with the volatiles from the lateral branch tips. Wild potatoes and some other plants can biosynthesis E- $\beta$-Farnesene as their secondary metabolism products naturally resist the pest of aphids to protect the plant itself [6]-[8]. Previous studies have shown that plant volatiles on insect host location to attract or reject play an important role, namely the "push and pull” role.

Myzus persicae (Sulzer) is one of the important pests of crabapple blade. Ornamental crabapple has excellent Ornamental value, such as flowers, foliage, fruit and so on and strong adaptability. Therefore it has been widely applied in a variety of landscape. But the leaves are often susceptible to aphids and we have to take chemical measures to prevent and control aphids. There were some individuals that can resistant aphids among half-sib groups we cultivate. Through the study of crabapple blade volatiles, this paper discusses the reason that there are different degrees of aphids' resistance and expects to find new method of prevention and control aphids.

\section{Materials and Methods}

\subsection{Materials}

There is a group of seedling obtained by Ralls and crabapple hybrid in 2005. The orchard irrigation condition is good, and the management level is consistent, also the Crabapple growth in good condition. In the growing season of 2012, we found these seedlings showed different resistance to aphid, so we divided these seedlings into three categories (Table 1). These seedlings became good test materials for the study of fruit trees with aphids feeding relationship.

The experiment was took place in State Key Laboratory for Crop Biology Shandong Agricultural University Tai'an, Shandong in June 2012. Tested materials are showed in Table 1. Samples are from ornamental orchard in Shandong Agriculture University, China, which has the good irrigation conditions and higher level of management.

\subsection{Methods}

Respectively 5 - 7 crabapple branches were randomly selected around the bough and brought back to the laboratory. These branches are insert water and different plant is separated to prevent aroma mixed. $7 \mathrm{~g}$ clean blades from retrieving branches in the conical flask with aluminium foil seal are adsorbed $40 \mathrm{~min}$ at room temperature with the aging extraction head, which are desorbed $2.5 \mathrm{~min}$ at $250^{\circ} \mathrm{C}$. And at the same time the GC-MS is launched to gain data.

The gas chromatographic condition: chromatographic column used was RestekRtx-5 $(30 \mathrm{~m} \times 0.32 \mathrm{~mm} \times 0.25$ $\mu \mathrm{m})$, Splitless injection of $1 \mu \mathrm{L}$ solution was performed at an injection port temperature of $250^{\circ} \mathrm{C}$. Helium was used as carrier gas at a flow rate of $3 \mathrm{ml} \cdot \mathrm{min}^{-1}$. The column temperature was maintained at $40^{\circ} \mathrm{C}$ for $2 \mathrm{~min}$, then programmed at $7^{\circ} \mathrm{C} / \mathrm{min}$ to $140^{\circ} \mathrm{C}$, then at $15^{\circ} \mathrm{C} / \mathrm{min}$ to $250^{\circ} \mathrm{C}$, which was held for $5 \mathrm{~min}$.

The transfer line temperature was $200^{\circ} \mathrm{C}$. The mass spectrometer was operated in electronimpact (EI) ioniza-

Table 1. The classification standard of crabapple resistance to aphids.

\begin{tabular}{ccc}
\hline Aphid Damage Level & Leaf Damage Degree & Aphids Resistance \\
\hline I level & Rarely aphids harm, no leaf curl phenomenon & High-resistance \\
II level & Mild aphids harm, leaf curl less than $50 \%$ & Moderate-resistance \\
III level & Serious aphids harm, leaf curl more than $50 \%$ & No-resistance \\
\hline
\end{tabular}


tion mode with electron energy of $70 \mathrm{eV}$. Scan range was 33 - $450 \mathrm{aMU}$.

Gas chromatography data processing system, the computer retrieval and NIST library (107 k compounds) and Wiley library (y320 k compounds, version 6.0), combined with the artificial map matching were used to confirm all kinds of chemical composition of volatile substances. According to peak area normalization method for their relative content, only when the matching degree and purity is greater than 80 (maximum 100) identification results will be reported.

\section{Results and Discussion}

\subsection{Volatiles of Crabapple Leaves in 21 Different Individuals}

Volatiles of leaves from twenty-one different crabapple individuals were evaluated with the method of HSSPME-GC-MS and search into computer library. There are one hundred eighty-six kinds of volatiles were detected with varied contents found in different individuals. And all plants contain a total of eight kinds of common components: 3-Hexen-1-ol, acetate, (Z)-, 4-Hexen-1-ol, (Z)-, n-Decanal, n-Tetradecane, .alpha.-Farnesene, Diethyl Phthalate, Oxime-, methoxy-phenyl- and Dibenzofuran-. Among them, the relative content of most is 3-Hexen-1-ol, acetate, (Z)-, respectively, accounting for the total leaf volatiles of $42.93 \%$, $34.63 \%, 60.77 \%$, 52.03\%, 53.73\%, 29.53\%, 51.48\%, 44.57\%, 58.94\%, 46.50\%, 64.48\%, 68.75\%, 47.09\%, 54.81\%, 54.28\%, $46.67 \%, 56.48 \%, 71.76 \%, 63.87 \%, 43.11 \%$ and $68.66 \%$. Followed by $4-H e x e n-1-o l$, (Z)-, accounting for the total leaf volatiles of $31.56 \%$, 24.04\%, 14.79\%, 15.16\%, 26.88\%, 28.02\%, 14.61\%, 18.14\%, 21.82\%, 24.13\%, $12.67 \%, 14.20 \%, 16.22 \%, 21.88 \%$, 21.93\%, $15.66 \%, 20.23 \%, 15.76 \%, 16.05 \%, 26.14 \%$ and $16.46 \%$. The two volatiles play a major role in the formation of leaf aroma and other relative content less volatile may constitute specific aroma between different individual (Table 2).

Table 2. Common leaf volatiles and its relative content in different individuals (\%).

\begin{tabular}{|c|c|c|c|c|c|c|c|c|}
\hline No. & $\begin{array}{l}\text { 4-Hexen-1-ol, } \\
\text { (Z)- }\end{array}$ & $\begin{array}{l}\text { Oxime-, } \\
\text { ethoxy } \\
\text {-phenyl- }\end{array}$ & $\begin{array}{l}\text { 3-Hexen-1-ol, } \\
\text { acetate, (Z)- }\end{array}$ & n-Decanal & n-Tetradecane & $\begin{array}{c}\text {.alpha. } \\
\text {-Farnesene }\end{array}$ & Dibenzofuran & $\begin{array}{c}\text { Diethyl } \\
\text { Phthalate }\end{array}$ \\
\hline 1 & 31.56 & 0.68 & 42.93 & 0.50 & 0.22 & 1.03 & 0.45 & 1.84 \\
\hline 2 & 24.04 & 0.65 & 34.63 & 0.33 & 0.15 & 4.52 & 0.26 & 1.18 \\
\hline 3 & 14.79 & 0.22 & 60.77 & 0.31 & 0.20 & 0.88 & 0.22 & 1.16 \\
\hline 4 & 15.16 & 4.15 & 52.03 & 0.45 & 0.81 & 2.25 & 0.55 & 7.46 \\
\hline 5 & 26.88 & 0.51 & 53.73 & 0.38 & 1.65 & 1.49 & 0.26 & 1.30 \\
\hline 6 & 28.02 & 0.41 & 29.53 & 0.30 & 0.13 & 3.53 & 0.28 & 1.16 \\
\hline 7 & 14.61 & 0.38 & 51.48 & 0.29 & 0.36 & 0.87 & 0.20 & 0.86 \\
\hline 8 & 18.14 & 3.45 & 44.57 & 0.16 & 0.29 & 2.49 & 0.29 & 1.02 \\
\hline 9 & 21.82 & 0.54 & 58.94 & 0.74 & 0.26 & 0.19 & 0.17 & 1.08 \\
\hline 10 & 24.13 & 0.46 & 46.50 & 0.37 & 0.21 & 1.09 & 0.27 & 1.17 \\
\hline 11 & 12.67 & 0.22 & 64.48 & 0.26 & 0.10 & 0.21 & 0.13 & 0.55 \\
\hline 12 & 14.20 & 0.19 & 68.75 & 0.25 & 0.39 & 0.40 & 0.16 & 0.64 \\
\hline 13 & 16.22 & 0.16 & 47.09 & 0.39 & 0.16 & 0.26 & 0.14 & 0.56 \\
\hline 14 & 21.88 & 0.21 & 54.81 & 0.25 & 0.19 & 0.21 & 0.22 & 0.91 \\
\hline 15 & 21.93 & 0.32 & 54.28 & 0.18 & 0.13 & 0.23 & 0.19 & 1.21 \\
\hline 16 & 15.66 & 0.16 & 46.67 & 0.20 & 0.16 & 2.57 & 0.19 & 0.87 \\
\hline 17 & 20.23 & 0.18 & 56.48 & 0.51 & 0.11 & 0.63 & 0.19 & 0.85 \\
\hline 18 & 15.76 & 0.37 & 71.76 & 0.14 & 0.07 & 0.03 & 0.14 & 0.62 \\
\hline 19 & 16.05 & 0.20 & 63.87 & 0.21 & 0.34 & 0.26 & 0.14 & 0.54 \\
\hline 20 & 26.14 & 0.27 & 43.11 & 0.39 & 0.40 & 1.35 & 0.17 & 0.80 \\
\hline 21 & 16.46 & 0.16 & 68.66 & 0.25 & 0.18 & 0.05 & 0.17 & 0.59 \\
\hline
\end{tabular}


According to chemical composition, the 186 volatiles can be divided into 45 hydrocarbons, 45 esters, 22 alcohols, 13 terpenoids, 9 aromatic, 8 aldehydes, 7 ketones, 1 ethers and 1 acids (Table 3). The most sorts is hydrocarbons and the largest relative content is esters, which are consistent with the previous studies [9]. Hydrocarbons, esters and alcohols, are the main volatiles that constitute crabapple blade aroma. The sort of hydrocarbons is the most, but the relative content of each substance is relative small. So hydrocarbons may be the main substance that constitute specific aroma between different individual.

\subsection{Differences of VOCs Sorts in Crabapple Individuals of Different Aphid Resistance}

VOCs sorts in crabapple individuals of different aphid resistance are different from hydrocarbons, alcohols and aldehydes. For high-resistance, moderate-resistance and no-resistance, ester volatiles account for $58.98 \%, 68.20 \%$ and $71.20 \%$, alcohols for $24.82 \%, 19.79 \%$ and $19.62 \%$ and aldehydes for $2.48 \%, 1.98 \%$ and $1.68 \%$ of the total volatiles, respectively. The more relative content of esters and aldehydes, and the lower the alcohols, the greater resistance to aphids.

The sort and relative content of the seven individuals of the same resistance is different (Table 4). Among the 7 individuals of no-resistance, 2 plant leaves no detected ketones, 4 plants were detected 1 ketone, 1 plants detected 2 ketones and 1 detected 4 ketones. The coefficient of variation in the 7 individuals of no-resistance is as high as $80.51 \%$. For the 7 high resistance plants, there are 19, 17, 15, 11, 13, 15 and 11 kinds of hydrocarbons, respectively, and the coefficient of variation is $20.74 \%$. The number of these volatiles is quite different, but their relative content is previous few.

\subsection{Different VOCs Component in Crabapple Individuals of Different Aphid Resistance}

Results showed that crabapple individuals of different aphid resistance have special volatiles in their blades (Table 5). The relative content of these special VOCs is not high, but it is the main manifestation in VOCs of aphid resistance. For example, 2-Isopropyl-5-methyl-1-hexanol was detected in all individuals of high-resistance, but not in no-resistance; $\beta$-Farnesene was in all no-resistance plants, instead of high-resistance, 3-Hexenal, (Z)was detected in 2 no-resistance plans, 5 moderate-resistances plants and all high-resistance plants (7 individuals). Meanwhile, there were 3 plants that were detected 2-Hexenal, (E)-, but the others were not. In conclusion, VOCs are different not only in different resistance plants, but also different individuals of the same aphid resistance plants.

\section{Discussions}

\subsection{Relationship between 3-Hexenal, (Z)- and the Aphids Resistance of Crabapple}

Host plant's VOCs play an important role in the selection process of the host plant in aphids. Plant green leaf volitiles generate aldehydes, alcohols and other small molecule compounds, such as n-hexanol, n-hexanal,

Table 3. VOCs types and relative content of 21 crabapple individuals leaves.

\begin{tabular}{ccc}
\hline VOCs sorts & Quantity (number) & Relative content (\%) \\
\hline Hydrocarbons & 80 & 5.89 \\
Esters & 45 & 66.13 \\
Alcohols & 22 & 21.41 \\
Terpenoids & 13 & 2.08 \\
Aromatic & 9 & 0.96 \\
Aldehydes & 8 & 2.03 \\
Ketones & 7 & 1.36 \\
Ethers & 1 & 0.35 \\
Acids & 1 & 0.03 \\
Total & 186 & 100.00 \\
\hline
\end{tabular}


Table 4. Differences of VOCs types in crabapple individuals of different resistance.

\begin{tabular}{|c|c|c|c|c|c|c|c|c|c|c|c|}
\hline \multirow{2}{*}{ VOCs solts } & \multirow{2}{*}{$\begin{array}{l}\text { Resistance } \\
\text { to aphids }\end{array}$} & \multirow{2}{*}{$\begin{array}{c}\text { Total } \\
\text { (number) }\end{array}$} & \multirow{2}{*}{$\begin{array}{c}\text { Relative } \\
\text { content (\%) }\end{array}$} & \multicolumn{7}{|c|}{ Sample number } & \multirow{2}{*}{$\begin{array}{c}\text { Variable } \\
\text { coefficien }\end{array}$} \\
\hline & & & & 1 & 2 & 3 & 4 & 5 & 6 & 7 & \\
\hline \multirow{3}{*}{ Hydrocarbons } & No-resistance & 45 & 6.63 & 14 & 14 & 14 & 12 & 13 & 16 & 13 & $9.14 \%$ \\
\hline & Moderate-resistance & 54 & 5.62 & 19 & 17 & 15 & 11 & 13 & 15 & 11 & $20.74 \%$ \\
\hline & High-resistance & 47 & 5.43 & 13 & 14 & 15 & 13 & 12 & 14 & 16 & $9.71 \%$ \\
\hline \multirow{3}{*}{ Esters } & No-resistance & 34 & 58.98 & 8 & 17 & 20 & 6 & 8 & 11 & 18 & $44.96 \%$ \\
\hline & Moderate-resistance & 34 & 68.20 & 6 & 11 & 18 & 16 & 16 & 19 & 17 & $31.32 \%$ \\
\hline & High-resistance & 36 & 71.20 & 17 & 20 & 16 & 18 & 19 & 18 & 17 & $7.53 \%$ \\
\hline \multirow{3}{*}{ Alcohol } & No-resistance & 15 & 24.82 & 10 & 6 & 5 & 4 & 5 & 6 & 3 & $39.94 \%$ \\
\hline & Moderate-resistance & 16 & 19.79 & 5 & 7 & 6 & 7 & 6 & 7 & 10 & $22.95 \%$ \\
\hline & High-resistance & 11 & 19.62 & 7 & 5 & 7 & 6 & 4 & 5 & 5 & $20.35 \%$ \\
\hline \multirow{3}{*}{ Terpenoids } & $\mathrm{N}$-resistance & 10 & 3.70 & 3 & 7 & 8 & 5 & 5 & 7 & 8 & $30.35 \%$ \\
\hline & Moderate-resistance & 7 & 1.24 & 4 & 4 & 3 & 7 & 4 & 4 & 5 & $28.73 \%$ \\
\hline & High-resistance & 7 & 1.30 & 4 & 7 & 4 & 3 & 4 & 6 & 4 & $30.57 \%$ \\
\hline \multirow{3}{*}{ Aldehydes } & No-resistance & 7 & 2.48 & 4 & 4 & 6 & 2 & 4 & 3 & 3 & $33.75 \%$ \\
\hline & Moderate-resistance & 7 & 1.98 & 1 & 5 & 3 & 5 & 4 & 7 & 5 & $44.10 \%$ \\
\hline & High-resistance & 6 & 1.68 & 2 & 3 & 5 & 4 & 6 & 5 & 5 & $32.20 \%$ \\
\hline \multirow{3}{*}{ Aromatic } & No-resistance & 7 & 1.48 & 5 & 1 & 2 & 1 & 4 & 2 & 2 & $62.25 \%$ \\
\hline & Moderate-resistance & 7 & 1.00 & 4 & 3 & 2 & 1 & 1 & 1 & 4 & $60.38 \%$ \\
\hline & High-resistance & 4 & 0.41 & 3 & 2 & 2 & 1 & 3 & 2 & 1 & $40.82 \%$ \\
\hline \multirow{3}{*}{ Ketones } & No-resistance & 4 & 1.55 & 2 & 1 & 0 & 1 & 1 & 1 & 0 & $80.51 \%$ \\
\hline & Moderate-resistance & 5 & 2.18 & 1 & 3 & 2 & 2 & 3 & 4 & 0 & $62.78 \%$ \\
\hline & High-resistance & 4 & 0.36 & 3 & 3 & 1 & 1 & 2 & 3 & 2 & $41.99 \%$ \\
\hline \multirow{3}{*}{ Acids } & No-resistance & 1 & 0.35 & 0 & 0 & 0 & 0 & 1 & 0 & 0 & - \\
\hline & Moderate-resistance & - & - & 0 & 0 & 0 & 0 & 0 & 0 & 0 & - \\
\hline & High-resistance & - & - & 0 & 0 & 0 & 0 & 0 & 0 & 0 & - \\
\hline \multirow{3}{*}{ Ethers } & No-resistance & - & - & 0 & 0 & 0 & 0 & 0 & 0 & 0 & - \\
\hline & Moderate-resistance & 1 & 0.03 & 1 & 0 & 0 & 0 & 0 & 0 & 0 & - \\
\hline & High-resistance & - & - & 0 & 0 & 0 & 0 & 0 & 0 & 0 & - \\
\hline \multirow{3}{*}{ Total } & No-resistance & 123 & 100 & 46 & 50 & 55 & 31 & 41 & 46 & 47 & $16.75 \%$ \\
\hline & Moderate-resistance & 131 & 100 & 40 & 51 & 49 & 49 & 47 & 57 & 52 & $10.52 \%$ \\
\hline & High-resistance & 115 & 100 & 49 & 54 & 50 & 46 & 50 & 53 & 50 & $5.23 \%$ \\
\hline
\end{tabular}

Z-3-Hexenal and so on, under the action of LOX and HPL [10]. Almost all chlorenchyma can release GLVs, which can induce nature enemy producing orientation reaction to host [11]. He, et al. [12] showed that E-2-hexenal has unsaturated carbonyl group and its electrophilic characteristics may be the main reason for its ability to induce plant defense responses, and even play a crucial role in plant diseases and insect pests control. In addition, E-2-Hexenal has antibacterial action and can be adsorbed on healthy leaves to further improve plants resistance. Small molecule compounds of six and similar carbon atoms, concluding aldehydes, alcohols, ketones and so on, such as 3-Hexenal, (Z)-, 2-Hexenal, (E)-, 1-Hexanol etc. are detected in all high-resistance plants, but only few no-resistance individuals. So we think that it is precisely a series of metabolic processes from aldehydes, ketones to esters that make the plants show resistance to aphids. 
Table 5. Different VOCs component in crabapple individuals of different aphid resistance.

\begin{tabular}{|c|c|c|c|c|c|c|c|c|c|c|c|c|c|c|c|c|c|c|c|c|c|}
\hline \multirow{3}{*}{ Compounds } & \multicolumn{21}{|c|}{ Relative Content (\%) } \\
\hline & \multicolumn{7}{|c|}{ Anti-Resistance } & \multicolumn{7}{|c|}{ Moderate-Resistance } & \multicolumn{7}{|c|}{ High-Resistance } \\
\hline & 1 & 2 & 3 & 4 & 5 & 6 & 7 & 8 & 9 & 10 & 11 & 12 & 13 & 14 & 15 & 16 & 17 & 18 & 19 & 20 & 21 \\
\hline $\begin{array}{l}\text { 3-Hexenal, } \\
\text { (Z)- }\end{array}$ & & 0.62 & 0.38 & & & & & & 0.75 & & 0.59 & 1.90 & 2.47 & 0.30 & 0.67 & 1.39 & 0.78 & 0.78 & 0.52 & 1.19 & 1.55 \\
\hline $\begin{array}{l}\text { 2-Hexenal, } \\
\text { (E)- }\end{array}$ & & 0.07 & 0.05 & & & & & & & & 0.09 & 0.27 & 0.38 & & & 0.20 & & 0.11 & 0.07 & 0.16 & 0.24 \\
\hline $\begin{array}{l}\text { 2-Isopropyl-5- } \\
\text { methyl-1- } \\
\text { hexanol }\end{array}$ & & & 0.03 & & & & & & & 0.03 & 0.03 & 0.05 & & 0.02 & & & & & & & \\
\hline $\begin{array}{l}\text { 2-Isopropyl-5- } \\
\text { methyl- }\end{array}$ & & & & & & & & & & & & & 0.03 & & 0.03 & 0.02 & 0.02 & 0.05 & 0.01 & 0.03 & 0.03 \\
\hline 1-heptanol & & & & & & & & & & & & & & & & & & & & & \\
\hline $\begin{array}{l}\text { 1,5-Heptadien- } \\
\text { 4-one, 3,3,6- } \\
\text { trimethyl- }\end{array}$ & & & & 6.42 & & & & & 0.22 & 0.30 & 0.02 & 0.10 & 0.34 & & 0.11 & 0.09 & & 0.04 & 0.02 & 0.13 & 0.09 \\
\hline $\begin{array}{l}\text { 2-Penten-1-ol, } \\
\text { acetate, (Z)- }\end{array}$ & & 0.75 & 0.35 & & & & 0.26 & & 0.38 & 0.30 & 0.94 & & 0.61 & 0.21 & 0.46 & 0.64 & 0.68 & & 0.72 & 0.60 & \\
\hline $\begin{array}{l}\text { 4-Hexen-1-ol, } \\
\text { acetate }\end{array}$ & & & 0.48 & & & & & & 1.01 & 0.83 & 0.03 & 0.02 & & & 0.66 & 0.28 & 0.46 & 0.04 & 0.02 & 0.33 & 0.02 \\
\hline $\begin{array}{l}\text { Propanoic acid, } \\
\text { 4-hexen- } \\
\text { 1-yl ester }\end{array}$ & & & & & & & & & & & & & & & 0.09 & & & 0.40 & 1.07 & 0.93 & \\
\hline $\begin{array}{l}\text {.beta.- } \\
\text { Farnesene }\end{array}$ & 0.29 & 0.13 & 0.40 & 0.49 & 0.12 & 0.70 & 0.06 & 0.11 & & & & & & & & & & & & & \\
\hline
\end{tabular}

\subsection{Relationship between $\beta$-Farnesene and the Aphids' Resistance of Crabapple}

In all chemical information aphids, the most important one is the alarm pheromone, and almost all aphids are releasing this sesquiterpene component. This alarm pheromone is a very effective chemical signal compounds, and can give a warning to predators. In addition, anti- $\beta$-farnesene is the main ingredient [13]-[15]. But some studies showed that aphids alarm pheromone, E- $\beta$-Farnesene, was one kind of VOCs that was released by plant [16]-[19]. Many plants, such as wild solanum tuberosum, synthetize E- $\beta$-Farnesene as secondary metabolites, naturaly resiste the aphids' pest and protect their self [6]. In this experiment, $\beta$-Farnesene was detected in all no-resistance and a small number of moderate-resistance plants, but not in high-resistance plants. Apparently, $\beta$-Farnesene has some relations to the existence of aphids. Therefore, we are not sure $\beta$-Farnesene detected was aphids secretions or the metabolin of plant leaf itself. To this, we will do a feedback test to verify the relationship between $\beta$-Farnesene and the Aphids resistance of crabapple.

\section{Conclusions}

This paper analyzed VOCs of crabapple (Malus sp.) leaves and compared the difference between different aphids' resistance. Hydrocarbons, alcohols and esters are the main volatiles. Esters' relative content is the highest and esters have the main role to the aroma of crabapple blade. The sort of hydrocarbons is the most and hydrocarbons may be the main substances that constitute specific aroma between different individual.

VOCs of crabapple leaf differ from individuals of different aphids' resistance. Special VOCs in high resistance plants contain: 3-Hexenal, (Z)-, 2-Hexenal, (E)-, 2-Isopropyl-5-methyl-1-hexanol, 2-Isopropyl-5-methyl1-heptanol, 1,5-Heptadien-4-one,3,3,6-trimethyl-, 2-Penten-1-ol, acetate, (Z)-, 4-Hexen-1-ol, acetate and Propanoic acid, 4-hexen-1-yl ester. And no-resistance plants all contain $\beta$-Farnesene.

\section{References}

[1] Zhou, Q. and Liang, G.-W. (2001) The Plant Volatiles and Their Effect on Host Location of Aphids. Entomological Knowledge, 38, 334-336.

[2] Dai, X.-F. and Ding, H.-J. (1996) The Relationships between Host Plant Volatiles and Pest Behavior. World Agriculture, 12, 27-28.

[3] Heil, M. (2010) Plastic Defense Expression in Plants. Evolutionary Ecology, 24, 555-569. 
http://dx.doi.org/10.1007/s10682-009-9348-7

[4] Kessler, A. and Baldwin, I.T. (2001) Defensive Function of Herbivore-Induced Plant Volatile Emissions in Nature. Science, 291, 2141-2144. http://dx.doi.org/10.1126/science.291.5511.2141

[5] Sun, F., Chi, D.-F., Yu, J., Gao, M. and Li, C.-D. (2010) Relationship between Volatiles from Korean Pine and Damage by Pissodes Nitidus. Journal of Northeast Forestry University, 3, 108-109.

[6] Gibson, R.W. and Pickett, J.A. (1983) Wild Potato Repels Aphids by Release of Aphid Alarm Pheromone. Nature, 302, 608-609. http://dx.doi.org/10.1038/302608a0

[7] Scutareanu, P., Drukker, B., Bruin, J., et al. (1997) Voatiles from Psylla-in-Fested Pear Trees and Their Possible Involvement in Attraction of Anthocorid Predators. Journal of Chemical Ecology, 23, 2241-2260. http://dx.doi.org/10.1023/B:JOEC.0000006671.53045.16

[8] Finidori-Logli, V., Anne-Geneviève, B. and Jean-Luc, C. (1996) Role of Plant Volatiles in the Search for a Host by Parasitoid Diglyphus Isaea (Hymenoptera Eulophidae). Journal of Chemical Ecology, 22, 541-558. http://dx.doi.org/10.1007/BF02033654

[9] Wu, M., Shen, X., Wang, C., Dong, Y., Han, T.-T. and Wang, R. (2012) Analysis of Leaf Volatiles from Crabapple (Malus sp.) Individuals of Different Juvenile Lengths. Scientia Agricultura Sinica, 45, 2438-2466.

[10] Deng, X.-J., Chen, X.-Y. and Du, J.-W. (2004) Plant Volatiles and Their Metabolic Engineering. Journal of Plant Physiology and Molecular Biology, 30, 11-18.

[11] Pichersky, E. and Gershenzon, J. (2002) The Formation and Function of Plant Volatiles: Perfumes for Pollinator Attraction and Defense. Current Opinion in Plant Biology, 5, 237-243. http://dx.doi.org/10.1016/S1369-5266(02)00251-0

[12] He, P.-Q., Liu, C.-Y., Hao, L.-H., Chen, K.-S. and Li, G.-Y. (2005) Volatile Organic Compounds and Plant against Pathogenic Disease. Plant Physiology Communications, 41, 105-110.

[13] Cui, L.-L. Control Effect of E- $\beta$-Farnesene, Z,E-Nepetalactone and Honeydew on Chinese Cabbage Aphid. Master's Thesis, Shandong Agricultural University, Shandong.

[14] Sun, Y.C., Su, J.W. and Ge, F. (2010) Elevated $\mathrm{CO}_{2}$ Reduces the Response of Sitobion avenae (Homoptera:Aphididae) to Alarm Pheromone. Agriculture, Ecosystems and Environment, 135, 140-147. http://dx.doi.org/10.1016/j.agee.2009.09.011

[15] Xiangyu, J.G., Zhang, F., Fang, Y.L., Kan, W., Zhang, G.X. and Zhang, Z.N. (2002) Behavioural Response of Aphids to the Alarm Pheromone Component (E)-Beta-Farnesene in the Field. Physiological Entomology, 27, 307-311. http://dx.doi.org/10.1046/j.1365-3032.2002.00302.x

[16] Turlings, T.C.J., Bernasconi, M., Bertossa, R., Bigler, F., Caloz, G. and Dorn, S. (1998) The Induction of Volatile Emissions in Maize by Three Herbivore Species with Different Feeding Habits: Possible Consequences for Their Natural Enemies. Biological Control, 11, 122-129. http://dx.doi.org/10.1006/bcon.1997.0591

[17] Agelopoulos, N.G., Hooper, A.M., Maniar, S.P., Pickett, J.A. and Wadhams, L.J. (1999) A Novel Approach for Isolation of Volatile Chemicals Released by Individual Leaves of a Plant in Situ. Journal of Chemical Ecology, 25, 14111425. http://dx.doi.org/10.1023/A:1020939112234

[18] Bruce, T.J.A., Birkett, M.A., Blande, J., Hooper, A.M., Martin, J.L., Khambay, B., Prosser, I., Smart, L.E. and Wadhams, L.J. (2005) Response of Economically Important Aphids to Components of Hemizygia petiolata Essential Oil. Pest Management Science, 61, 1115-1121. http://dx.doi.org/10.1002/ps.1102

[19] Heuskin, S., Godin, B., Leroy, P., Capella, Q., Wathelet, J.P., Verheggen, F., Haubruge, E. and Lognay, G. (2009) Fast Gas Chromatography Characterisation of Purified Semiochemicals from Essential Oils of Matricaria chamomilla L. (Asteraceae) and Nepeta cataria L. (Lamiaceae). Journal of Chromatography A, 1216, 2768-2775.

http://dx.doi.org/10.1016/j.chroma.2008.09.109 
Scientific Research Publishing (SCIRP) is one of the largest Open Access journal publishers. It is currently publishing more than 200 open access, online, peer-reviewed journals covering a wide range of academic disciplines. SCIRP serves the worldwide academic communities and contributes to the progress and application of science with its publication.

Other selected journals from SCIRP are listed as below. Submit your manuscript to us via either submit@scirp.org or Online Submission Portal.
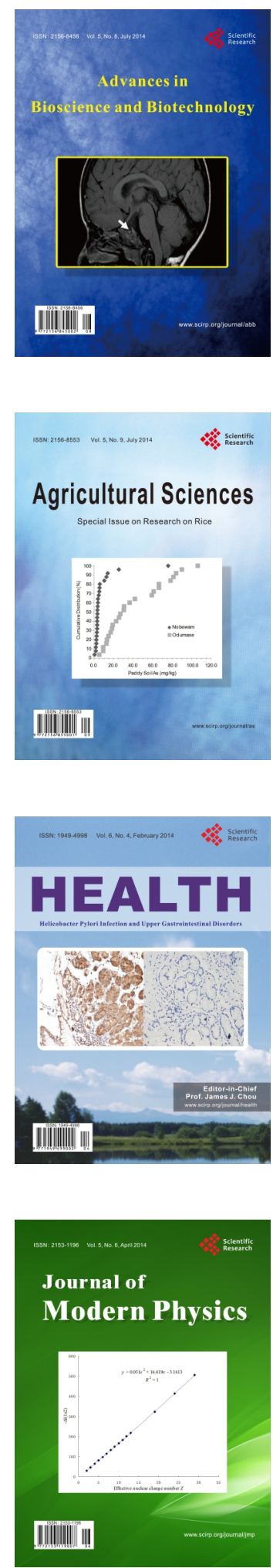
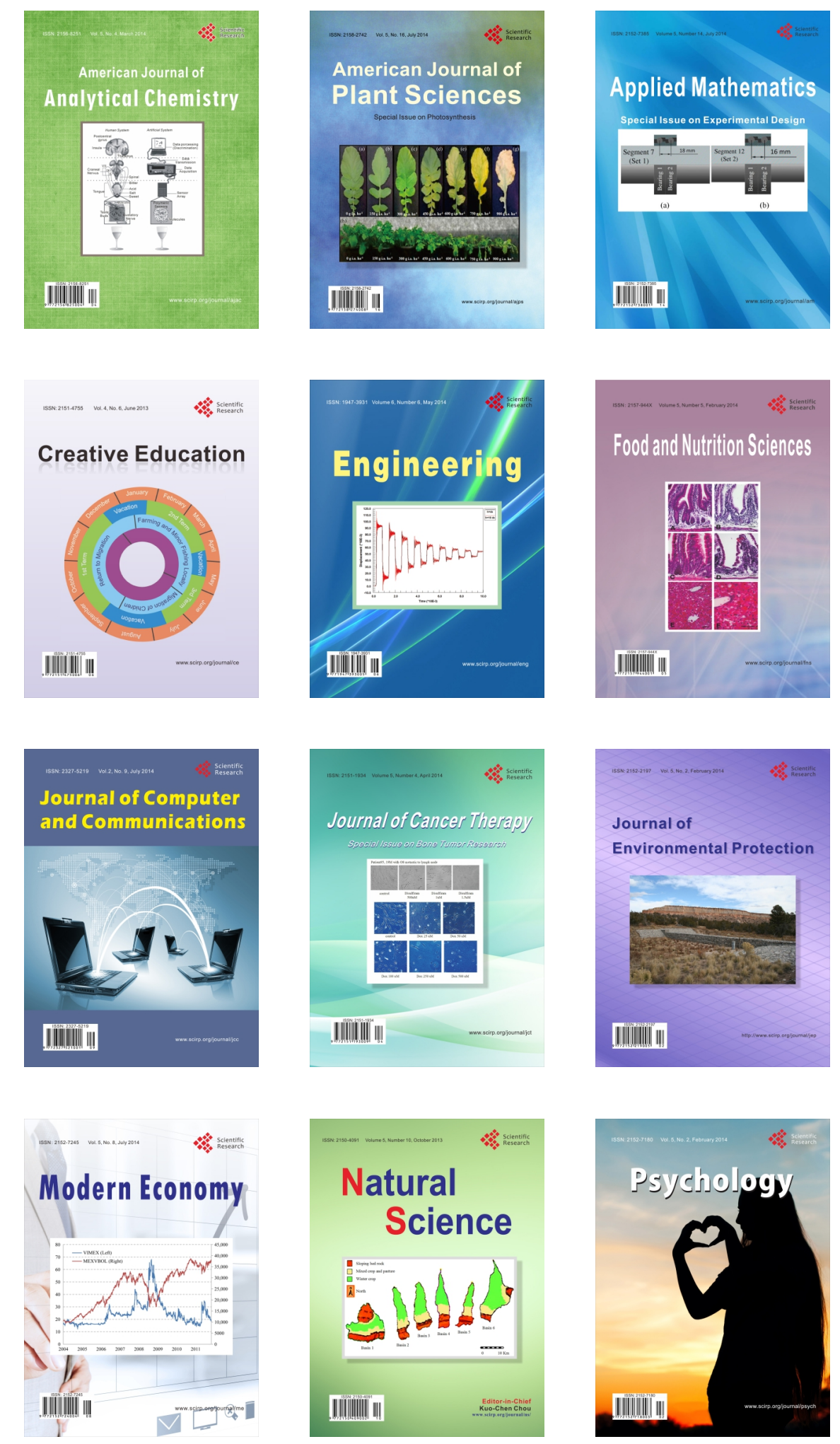